\title{
Circadian Rhythm of Cardiovascular Disease: The Potential of Chronotherapy With Aspirin
}

\author{
Marleen Buurma ${ }^{1 *}$, Jeske J. K. van Diemen ${ }^{2}$, Abel Thijs ${ }^{2}$, Mattijs E. Numans ${ }^{1}$ and \\ Tobias N. Bonten ${ }^{1}$ \\ ${ }^{1}$ Department of Public Health and Primary Care, Leiden University Medical Center, Leiden, Netherlands, ${ }^{2}$ Department of \\ Internal Medicine, Amsterdam University Medical Center, Amsterdam, Netherlands
}

OPEN ACCESS

Edited by:

Marie Lordkipanidzé,

Université de Montréal, Canada

Reviewed by:

Paola Patrignani,

Università degli Studi G. d'Annunzio

Chieti e Pescara, Italy

Erik Lerkevang Grove,

Aarhus University Hospital, Denmark

*Correspondence:

Marleen Buurma

m.buurma.HAGK@/umc.n

Specialty section:

This article was submitted to

Atherosclerosis and Vascular

Medicine,

a section of the journal

Frontiers in Cardiovascular Medicine

Received: 09 April 2019

Accepted: 04 June 2019

Published: 20 June 2019

Citation:

Buurma M, van Diemen JJK, Thijs A, Numans ME and Bonten TN (2019)

Circadian Rhythm of Cardiovascular

Disease: The Potential of

Chronotherapy With Aspirin.

Front. Cardiovasc. Med. 6:84

doi: 10.3389/fcvm.2019.00084
Almost all the systems in our body adhere to a daily $24 \mathrm{~h}$ rhythm. The cardiovascular system is also affected by this $24 \mathrm{~h}$ rhythm. In the morning there is a change in various cardiovascular processes, including platelet aggregability. These changes may play a role in the relative excess of early morning cardiovascular events. The number of recurrent cardiovascular diseases (CVD) could, in theory, be reduced by responding to this $24 \mathrm{~h}$ rhythm with timed medication intake (chronotherapy), which also applies to aspirin. Multiple studies on chronotherapy with low-dose aspirin are promising, showing a decrease in early morning platelet activity with evening intake compared with morning intake. However, in order to further demonstrate its clinical impact, randomized trials with cardiovascular events as a primary outcome are needed. This review discusses the available evidence of the effects of circadian rhythm on CVD and the potential positive effect of chronotherapy with aspirin.

Keywords: aspirin, cardiovascular disease, platelet aggregation, circadian rhythm, chronotherapy

\section{INTRODUCTION}

In the past centuries, more and more has been discovered about the different mechanisms in our body as well as how to apply this in our medical treatment regimes. This article will discuss one of those discoveries, namely the circadian rhythm and its influence on the development of acute events of cardiovascular disease (CVD). Platelet aggregation is one of the mechanisms responsible for the development of adverse cardiovascular events. In current medicine, antiplatelet medication is the cornerstone of prevention of recurrent cardiovascular events. Recent studies assessed whether optimal timing of intake of medication, such as aspirin, can give a further reduction of CVD.

\section{THE DISCOVERY OF ASPIRIN AND CIRCADIAN RHYTHMS}

Around 2,400 years ago Hippocrates was one of the first who described the analgesic effects of willow bark (1). Aspirin, a medicine derived from the willow bark, is still one of the most widespread used medications in the world (2). It is sometimes called the wonder drug, because of its different properties like antipyretic, analgesic, antiplatelet, anti-inflammatory, and even anti-cancer effects $(1,3)$.

These observations were already made well before the use of evidence-based medicine. In 1563, Reverend Edward Stone carried out a carefully planned clinical study on $\sim 50$ patients suffering from inflammatory disorders and pains with encouraging results $(1,4)$. This research provided the first scientific basis for the common use of willow bark. 
The next step in the scientific discovery was the isolation of the active ingredient of the willow bark (1). In 1897, acetylsalicylic acid was created by Felix Hoffman, by modifying salicylic acid by acetylation, and named it Aspirin. This acetylated salicylic acid also provided for the properties of Aspirin to prevent (recurring) CVD events (4).

In 1950, before the exact working mechanism of aspirin was known, the family doctor Lawrence Craven wrote about his experience with aspirin in a number of American journals. In one of his articles, he mentioned that in patients using a higher dosage of aspirin impregnated chewing gum than that he prescribed after undergoing a tonsillectomy, more complications such as bleeding occurred. Following this, he reasoned that aspirin might have a thrombolytic effect (1).

Twenty years later (1971), Vane and co-workers discovered that aspirin inhibits the synthesis of prostaglandin. This mechanism explains the antipyretic, anti-inflammatory, and antiplatelet effects of aspirin (5). For this discovery, Vane received the Nobel prize for Medicine in 1982. Even today, scientists are discovering new properties of aspirin and are reassessing its value in the light of new knowledge of mechanisms in pathophysiology. This includes recent knowledge about circadian rhythms in our body, which seems a new opportunity to optimize today's medical treatment for CVD.

For a long time, it was thought that almost everything in our body occurred randomly. In 1984, a gene was identified in fruit flies, that ensures the $24 \mathrm{~h}$ rhythm (circadian rhythm) in physiological processes, like hormone concentrations (6). The circadian rhythm in physiology and human behavior (e.g., sleep, activity, and eating), are essential for all organisms enabling them to anticipate and adapt to the natural environment $(7,8)$.

This circadian rhythm is controlled by the central or master clock and peripheral clocks. The central clock situated in the hypothalamus in the central nervous system, called the suprachiasmatic nucleus (SCN), coordinates the expression of the clock genes throughout the body (9). This central clock is mainly driven by the alternation of light and dark $(10,11)$. The peripheral clocks can be found in almost any tissue of the body, including the cardiovascular system $(11,12)$. An example of one of those genes is the CLOCK gene. This gene affects, among other things, platelet aggregation, and the expression of plasminogen activator inhibitor-1 (PAI-1). A mutation in the CLOCK gene can result in several changes. For example, the daily variation in platelet aggregation disappeared in CLOCK mutant mice. Besides, mice with CLOCK mutation had reduced and non-rhythmic secretion of PAI- 1 by the endothelial cells (7).

The internal clock has a lot of influence on the functioning of our body. Chronic disruption of this clock, for example by shift work, is thought to be related to metabolic syndrome, cancer, diabetes, and cardiovascular disease $(7,9,13)$.

\section{CARDIOVASCULAR DISEASE AND CIRCADIAN RHYTHM}

The human cardiovascular system has different activity patterns with cycles of $24 \mathrm{~h}$, including heart rate, blood pressure,
TABLE 1 | Important changes in cardiovascular processes during the morning.

\begin{tabular}{|c|c|c|}
\hline $\begin{array}{l}\text { Cardiovascular } \\
\text { processes }\end{array}$ & $\begin{array}{l}\text { Activation during } \\
\text { morning hours }\end{array}$ & $\begin{array}{l}\text { Negative effect on cardiovascular } \\
\text { disease }\end{array}$ \\
\hline $\begin{array}{l}\text { Sympathetic } \\
\text { tone }\end{array}$ & Increased & $\begin{array}{l}\text { Increase in blood pressure, heart rate, } \\
\text { and vasoconstriction (15). }\end{array}$ \\
\hline $\begin{array}{l}\text { Parasympathetic } \\
\text { function }\end{array}$ & Decreased & $\begin{array}{l}\text { Increase in heart rate and } \\
\text { vasoconstriction (15). }\end{array}$ \\
\hline $\begin{array}{l}\text { Blood } \\
\text { pressure }\end{array}$ & Increased & $\begin{array}{l}\text { There is an associations between an } \\
\text { increase in blood pressure and } \\
\text { ischemic heart disease and } \\
\text { stroke (16). }\end{array}$ \\
\hline Heart rate & Increased & $\begin{array}{l}\text { High resting heart rate is associated } \\
\text { with adverse cardiovascular events } \\
\text { (17). }\end{array}$ \\
\hline $\begin{array}{l}\text { Vascular } \\
\text { endothelial } \\
\text { function }\end{array}$ & Decreased & $\begin{array}{l}\text { Endothelial dysfunction is associated } \\
\text { with atherosclerotic plaque } \\
\text { formation (18). }\end{array}$ \\
\hline $\begin{array}{l}\text { Platelet } \\
\text { aggregation }\end{array}$ & Increased & $\begin{array}{l}\text { A higher platelet aggregation } \\
\text { increases the change of the formation } \\
\text { of blood clots and thereby, adverse } \\
\text { cardiovascular events (19). }\end{array}$ \\
\hline $\begin{array}{l}\text { Thrombolytic } \\
\text { activity }\end{array}$ & Decreased & $\begin{array}{l}\text { Lower thrombolytic activity increases } \\
\text { the change of the formation of blood } \\
\text { clots, and thereby adverse } \\
\text { cardiovascular events (20). }\end{array}$ \\
\hline
\end{tabular}

circulating catecholamines, blood coagulation markers, vascular endothelial function, and autonomic nervous system $(8,14)$. In the morning there is a change in a number of cardiovascular processes (Table 1). Importantly, these rhythm modifications in the morning correspond to the occurrence of CVD. An apparent increase in the number of adverse cardiovascular events is observed during morning hours (06.00-12.00 h), such as stroke, myocardial infarction, ventricular arrhythmias, and sudden cardiac arrest $(8,21,22)$. Patients who had a heart attack during morning hours will mostly have a larger infarct size and worse prognosis, compared with patients having a myocardial infarction during the rest of the day (23).

\section{AUTONOMIC NERVOUS SYSTEM AND CIRCADIAN RHYTHM}

The autonomic nervous system plays a vital role in physiological and pathological responses of the cardiovascular system. The sympathetic system induces an increase in heart rate, myocardial contractility, and peripheral resistance. The parasympathetic system, on the other hand, has the opposite effect, where it primarily causes a reduction in heart rate and, to a lesser extent, a decrease in cardiac contractility (15). The parasympathetic and sympathetic system both follow a circadian rhythm. Whereas, the parasympathetic activity is more pronounced during the night, the sympathetic system has a peak in activity during the morning. Moreover, this early morning peak coincides with a high sensitivity of vascular receptors $(14,21)$. This morning peak of the sympathetic nervous system and the increased activity of the renin-angiotensin-aldosterone axis along with the decreased parasympathetic system contribute to the rise in blood pressure 
and heart rate in the morning (21). These changes in the morning probably add to the increased incidence of CVD during the same time period (8).

\section{BLOOD PRESSURE AND CIRCADIAN RHYTHM}

Blood pressure follows a $24 \mathrm{~h}$ rhythm. In the morning there is a rise, which reaches a plateau around $11 \mathrm{am}$. Then it gradually decreases, and around midnight it reaches its lowest value (24). Blood pressure usually is about 10 to $20 \%$ lower while sleeping than during daytime (25). The change in blood pressure is related to the change in activity of the sympathetic nervous system running parallel to the normal sleep-wake cycle (24). Night-time blood pressure is lower due to the reduction of sympathetic tone and the parallel increase in vagal activity during the sleep period. External factors influence blood pressure as well, such as physical activity, emotions, intake of food and drinks, and the variation in light and dark (20).

The time frame of the rise in blood pressure in the morning coincides with the increase in the number of cardiovascular events in the morning (8). Due to the rise in blood pressure in the morning, vulnerable plaques in arteries are more prone to rupture, which can lead to acute adverse cardiovascular events (26). Not only the morning blood pressure rise increases the risk of developing CVD. Research has shown that having continues high blood pressure during nighttime (non-dipping) increases this risk as well. As a matter of fact, it is the lack of a nightly drop in blood pressure which is a risk of the development of CVD $(8,24)$. The MAPEC study showed that, with the use of chronotherapy, nighttime blood pressure would be reduced, thereby diminishing the risk of CVD (27).

\section{VASCULAR ENDOTHELIUM AND CIRCADIAN RHYTHM}

The vascular endothelium has anti-atherosclerotic functions, plays a role in the aggregation of platelets and regulates the patency of vessels via excretion of nitrogen oxide $(8,28)$. All of these factors influence the cardiovascular system, and therefore, dysfunction may lead to adverse cardiovascular events (8). Dysfunction of the endothelium results in an imbalance in the production and consumption of nitrogen oxide (18). The endothelium-dependent vasodilator function is normally reduced during morning hours, because of the lower production of nitrogen oxide (20). This vasodilating function of the endothelium protects against diseases such as hypertension, stroke, and myocardial infarction. The deterioration of this function might contribute to the morning peak of $\operatorname{CVD}(8,28,29)$.

\section{BLOOD CLOTTING AND CIRCADIAN RHYTHM}

The ability of blood to form clots can be life-saving during a bleeding event. On the other side, the formation of clots in blood vessels can also lead to ischemic stroke, myocardial infarction, and sudden cardiac arrest. As a counterpart to the development of blood clot, there is thrombolysis, which helps to break down clots and keep blood vessels open. The balance between clotting and bleeding tendency changes during the day. Coagulation is increased during morning hours, partly because platelet aggregation and platelet surface activation markers experience a peak in the morning between 06.00 and $12.00 \mathrm{~h}(2,30,31)$. In this same period, there is reduced thrombolysis which can partly be explained by a reduced concentration of plasmin-plasmin inhibitor complex in blood during morning hours (20). Secondly by an increased level of plasminogen activator inhibitor-1 (PAI1). PAI-1 is one of the most important inhibitors of plasma fibrinolytic activity. So, increased PAI-1 concentrations enhance the chance of the development of blood clots $(32,33)$. These phenomena lead to an increased risk of developing blood clots in the morning hours, possibly contributing to the peak of CVD in this period $(2,8,33)$.

The development of CVD is influenced by factors such as continuous interaction between the various circadian phases in the body, the behavior of the individual such as physical exercise and personal risk factors. The circadian rhythms of different processes in the body, such as vagal withdrawal, sympathetic activation, and increased blood clotting, have a homeostatic advantage in most circumstances, anticipating the expected behavioral changes in the morning, and other periods of the day. But in a person susceptible to CVD, the circadian change in the morning can exceed the theoretical risk threshold, which leads to the development of adverse cardiovascular events. The question is whether the circadian rhythm is actually the cause of CVD or whether it reveals the underlying vulnerability $(8,33)$.

Based on currently available evidence we believe that the circadian rhythms and their influence on CVD, as described above, should be taken into account in the treatment of CVD. Also, the pharmacokinetics of the drug is maybe influenced by this rhythm (34). By reckoning the importance of the circadian rhythm in total during treatment, this might lead to increased effectiveness and fewer side effects. Furthermore, the effectiveness of medicines can also be influenced by comedication. A recent study shows that coadministration of low-dose aspirin and atorvastatin, and possibly other statins, reduces cardiovascular events (35). Still, an important role may be reserved for using the circadian rhythm for drug treatment, such as with acetylsalicylic acid.

\section{ASPIRIN AND TIME OF INTAKE}

Platelets are key players in the development of arterial thrombosis. Consequently, aspirin is a cornerstone of secondary prevention because it inhibits platelets. The majority of patients take maintenance doses of 75-325 mg once a day in the morning, after awakening (36). However, research shows that, despite the improvement of lifestyle and drug prevention, $10-33 \%$ of these patients have a recurrence of an adverse cardiovascular event within 5 years after their first event (37). The reasons for this recurrence is not completely clear, but probably multifactorial. In theory, it could be partially explained due to the pharmacokinetic 
properties of aspirin and the circadian physiology of platelets. Aspirin is absorbed reasonably quickly with a Tmax of $0.5-2 \mathrm{~h}$ for non-enteric-coated aspirin and 3-4 h for enteric-coated aspirin. But also rapidly excreted with a half-life of acetylsalicylic acid of $\sim 20 \mathrm{~min}$ (38). The current once-daily regimen is associated with a slow increase in platelet activity within the $24 \mathrm{~h}$ dosing interval (39-41). A likely explanation for this phenomenon could be the production of new platelets (42). These new platelets are released at a rate of $10-15 \%$ per day $(43,44)$. Because of the pharmacokinetic properties of aspirin, the cyclooxygenase1 (COX-1) of the newly released platelets is not inhibited, and so they are able to form blood clots. Previous studies have shown that $95 \%$ of all platelets' COX-1 must be inhibited to achieve effective reduction of platelet aggregation $(45,46)$. This percentage is supported by a recent study in which insufficient inhibition of platelet aggregation was seen $24 \mathrm{~h}$ after morning aspirin intake in $25 \%$ of patients with CVD (40). The production and delivery of these new platelets follow a circadian rhythm with peak release in the late night and early morning (47). This, too, coincides with the occurrence of adverse cardiovascular events (8, $21,22)$. Therefore, it can be essential to ensure adequate platelet inhibition during the morning hours. By taking the aspirin on awakening, $10 \%$ uninhibited platelets are present during the morning hours. By responding to the circadian rhythm and taking aspirin at bedtime, the proportion of unrestrained platelets during the morning hours would theoretically be reduced to 5\% (2). This results in increased inhibition of the platelet reactivity during morning hours, and possibly a reduction in adverse cardiovascular events.

Several studies try to accomplish a further decrease in the number of recurrences of adverse cardiovascular events by further reducing the number of uninhibited platelets. These studies are assessing the effect on platelet aggregation by increasing dosage, increasing intake frequency, and the use of chronotherapy.

\section{Increasing Aspirin Dosage}

When comparing standard morning low-dose aspirin with a higher dosage on platelet aggregation, the effectiveness of the increase differ. In most studies, the inhibition of the sTxB2 shows sufficient inhibition at a dosage between 80 and $325 \mathrm{mg}$ aspirin per day (48-52). However, three trials reported higher sTxB2 inhibition after dosages above $325 \mathrm{mg}$ of aspirin in comparison with a standard once daily low-dose regimen (52-54). There was a small to no increase in platelet inhibition measured by the Light Transmission Aggregometry if the dosages were above $325 \mathrm{mg}$ (52, 54-57). The results of platelet aggregation measured with the Platelet Function Analyzer and VerifyNow were in line with the $\mathrm{sTxB}_{2}$ results: two trials demonstrated sufficient levels of platelet inhibition with once-daily dosages of $75-325 \mathrm{mg}$ of aspirin $(50,56,58)$.

\section{Increased Intake Frequency of Aspirin}

Regarding the increase of the intake frequency, a higher sTxB2 inhibition was reported in three studies, when intake was increased to more than one intake per day in comparison with the standard once daily low-dose regimen $(50,59,60)$. Capodanno et al. reported a superior inhibition when intake was increased to more than once-daily of aspirin in comparison with the standard once-daily dosing, measured by the Light Transmission Aggregometry and VerifyNow (50). On the other hand, five trials did not demonstrate superiority in the level of inhibition by increasing the intake frequency of aspirin $(49,59,61-63)$. In addition, when measuring the platelets aggregation by Platelet Function Analyzer, a difference was seen between patients with stable CVD and healthy volunteers $(59,64)$. In patients with stable CVD, a significant decrease in platelet aggregation was seen when comparing intake of once daily with twice a day (64). This difference was not demonstrated in healthy volunteers (59).

\section{Chronotherapy of Aspirin}

Two randomized cross-over trials on chronotherapy concerning platelet function inhibition suggested a superior $\mathrm{sTx}_{2}$ inhibition after once-daily evening intake of low-dose aspirin in comparison with morning intake $(2,59)$. van Diemen et al. reported an increased platelet inhibition, measured with Light Transmission Aggregometry, after low-dose aspirin intake in the evening in comparison with the standard low-dose aspirin once daily in the morning (65). When measuring the platelets aggregation by Platelet Function Analyzer, a different effect on platelet aggregation was found between patients with stable CVD and healthy volunteers. In stable cardiovascular patients, a statistically significantly higher level of platelet inhibition was demonstrated after evening intake, whereas a trial conducted in healthy subjects did not show a difference $(59,65)$.

One parallel RCT and three randomized cross-over trials reported more platelet inhibition, measured by the VerifyNow, after evening intake of low-dose aspirin compared with the standard once daily morning dosing $(2,59,66,67)$.

\section{The Different Intake Regimens}

When analyzing these different studies on platelet aggregation, one could conclude that an aspirin dosage between 75 and $325 \mathrm{mg}$ once daily provides sufficient platelet inhibition in early morning hours $(48-52,56,58,59,61-63)$. Especially when we consider that changes in the dosage, frequency, or intake time, in addition to their positive effect on platelet aggregation, may also give a higher chance of side effects. When increasing the dosage above $325 \mathrm{mg}$ once daily minor improvement of platelet inhibition is obtained (52-56). Besides, the risk of side effects such as gastrointestinal bleeding increases with increasing dosage (68). Increasing the intake frequency seems also beneficial on the level of platelet inhibition $(50,59,60,64)$. Again, the total daily dose should not exceed $325 \mathrm{mg}$, due to the increased chance of complications. Beside, adherence deteriorated with an increasing number of intake moments (69). Importantly, the application of chronotherapy showed, in most of the studies, a higher level of platelet inhibition when comparing the evening intake with the standard once-daily morning intake $(2,59,65-67)$. The chance of side effects with the use of low-dose aspirin is similar between the different intake regimens (70). But there have been few longterm studies on the effects of increased intake frequency and chronotherapy so far. However, the evidence for chronotherapy seems hitherto to be the most consistent compared with the 
other interventions (increasing dosages and intake frequency). Chronotherapy probably has a lower expectancy of side effects on the long-term, because there is no increase in dosage.

\section{CONCLUSION}

It is clear that the cardiovascular system of our body follows a circadian rhythm. Several studies have shown that adverse cardiac events also follow a circadian rhythm, with a vulnerable period in the early-morning hours. The described circadian processes of the cardiovascular system, each with its own rhythm, presumably all contribute to the development of adverse cardiac events. It is essential to investigate how the medical profession can respond to this circadian rhythm in the treatment of CVD leading to increased effectiveness of treatments and/or fewer side effects. The available evidence already shows positive effects of chronotherapy, for instance by reducing nighttime blood pressure. Also, recent studies on chronotherapy suggest

\section{REFERENCES}

1. Mueller RL, Scheidt S. History of drugs for thrombotic disease. Discovery, development, and directions for the future. Circulation. (1994) 89:432-49. doi: 10.1161/01.CIR.89.1.432

2. Bonten TN, Saris A, van Oostrom MJ, Snoep JD, Rosendaal FR, Zwaginga J, et al. Effect of aspirin intake at bedtime versus on awakening on circadian rhythm of platelet reactivity. A randomised cross-over trial. Thromb Haemost. (2014) 112:1209-18. doi: 10.1160/th14-05-0453

3. Rothwell PM, Wilson M, Price JF, Belch JF, Meade TW, Mehta Z. Effect of daily aspirin on risk of cancer metastasis: a study of incident cancers during randomised controlled trials. Lancet. (2012) 379:1591-601. doi: 10.1016/S0140-6736(12)60209-8

4. Miner J, Hoffhines A. The discovery of aspirin's antithrombotic effects. Tex Heart Inst J. (2007) 34:179-86.

5. Vane JR. Inhibition of prostaglandin synthesis as a mechanism of action for aspirin-like drugs. Nature. (1971) 231:232-5. doi: 10.1038/newbio231 $232 \mathrm{a} 0$

6. Burki T. Nobel Prize awarded for discoveries in circadian rhythm. Lancet. (2017) 390:e25. doi: 10.1016/S0140-6736(17)32661-2

7. Pritchett D, Reddy AB. Circadian clocks in the hematologic system. J Biol Rhythms. (2015) 30:374-88. doi: 10.1177/0748730415592729

8. Thosar SS, Butler MP, Shea SA. Role of the circadian system in cardiovascular disease. J Clin Invest. (2018) 128:2157-67. doi: 10.1172/JCI80590

9. Kuehn BM. The heart's circadian rhythms point to potential treatment strategies. Circulation. (2016) 134:1907-8. doi: 10.1161/CIRCULATIONAHA.116.026039

10. Takeda N, Maemura K. The role of clock genes and circadian rhythm in the development of cardiovascular diseases. Cell Mol Life Sci. (2015) 72:3225-34. doi: 10.1007/s00018-015-1923-1

11. Crnko S, Cour M, Van Laake LW, Lecour S. Vasculature on the clock: circadian rhythm and vascular dysfunction. Vasc Pharmacol. (2018) 108:1-7. doi: 10.1016/j.vph.2018.05.003

12. Boivin DB, Boudreau P. Impacts of shift work on sleep and circadian rhythms. Pathol-Biol. (2014) 62:292-301. doi: 10.1016/j.patbio.2014. 08.001

13. Wehrens SM, Hampton SM, Skene DJ. Heart rate variability and endothelial function after sleep deprivation and recovery sleep among male shift and non-shift workers. Scand J Work Environ. Health. (2012) 38:171-81. doi: $10.5271 /$ sjweh. 3197

14. Cooke-Ariel H. Circadian variations in cardiovascular function and their relation to the occurrence and timing of cardiac events. Am J Health-Syst Pharm. (1998) 55(Suppl. 3):S5-11. doi: 10.1093/ajhp/55.suppl_3.S5 that low-dose aspirin taken at bedtime compared with intake on awakening can improve platelet inhibition during morning hours. There is a need for randomized controlled trials with cardiovascular events and side-effects as endpoints, to further supports the promising chronotherapy hypothesis.

\section{AUTHOR CONTRIBUTIONS}

$\mathrm{MB}, \mathrm{TB}, \mathrm{JD}, \mathrm{AT}$, and $\mathrm{MN}$ made substantial contributions to conception and design and gave final approval of the version to be submitted and any revised version. $M B$, $\mathrm{JD}$, and $\mathrm{TB}$ participated in drafting the article. TB, AT, and $\mathrm{MN}$ participated in revising it critically for important intellectual content.

\section{FUNDING}

This work was supported by ZonMw (grant number 848016006).

15. La Rovere MT, Christensen JH. The autonomic nervous system and cardiovascular disease: role of n-3 PUFAs. Vasc Pharmacol. (2015) 71:1-10. doi: 10.1016/j.vph.2015.02.005

16. Rapsomaniki E, Timmis A, George J, Pujades-Rodriguez M, Shah $\mathrm{AD}$, Denaxas $\mathrm{S}$, et al. Blood pressure and incidence of twelve cardiovascular diseases: lifetime risks, healthy life-years lost, and agespecific associations in 1.25 million people. Lancet. (2014) 383:1899-911. doi: 10.1016/S0140-6736(14)60685-1

17. Zhang D, Wang W, Li F. Association between resting heart rate and coronary artery disease, stroke, sudden death and noncardiovascular diseases: a metaanalysis. Canad Med Assoc J. (2016) 188:e384-92. doi: 10.1503/cmaj.160050

18. Widmer RJ, Lerman A. Endothelial dysfunction and cardiovascular disease. Glob Cardiol Sci Pract. (2014) 2014:291-308. doi: 10.5339/gcsp.2014.43

19. Willoughby S, Holmes A, Loscalzo J. Platelets and cardiovascular disease. Euro J Cardiovasc Nurs. (2002) 1:273-88. doi: 10.1016/S1474-51510200038-5

20. Takeda N, Maemura K. Circadian clock and vascular disease. Hypertens Res. (2010) 33:645-51. doi: 10.1038/hr.2010.68

21. Manfredini R, Boari B, Smolensky MH, Salmi R, la Cecilia O, Maria Malagoni A, et al. Circadian variation in stroke onset: identical temporal pattern in ischemic and hemorrhagic events. Chronobiol Int. (2005) 22:417-53. doi: 10.1081/CBI-200062927

22. Butt MU, Zakaria M, Hussain HM. Circadian pattern of onset of ischaemic and haemorrhagic strokes, and their relation to sleep/wake cycle. JPMA. (2009) 59:129-32.

23. Suarez-Barrientos A, Lopez-Romero P, Vivas D, Castro-Ferreira F, NunezGil I, Franco E, et al. Circadian variations of infarct size in acute myocardial infarction. Heart. (2011) 97:970-6. doi: 10.1136/hrt.2010.212621

24. Neutel JM. The importance of 24-h blood pressure control. Blood Pressure Monitor. (2001) 6:9-16. doi: 10.1097/00126097-200102000-00002

25. Cuspidi C, Sala C, Tadic M, Gherbesi E, De Giorgi A, Grassi G, et al. Clinical and prognostic significance of a reverse dipping pattern on ambulatory monitoring: an updated review. J Clin Hypertens. (2017) 19:71321. doi: $10.1111 /$ jch. 13023

26. Atkinson G, Jones $\mathrm{H}$, Ainslie PN. Circadian variation in the circulatory responses to exercise: relevance to the morning peaks in strokes and cardiac events. Euro J Appl Physiol. (2010) 108:15-29. doi: 10.1007/s00421-009-1243-y

27. Hermida RC, Ayala DE, Mojon A, Fernandez JR. Influence of circadian time of hypertension treatment on cardiovascular risk: results of the MAPEC study. Chronobiol Int. (2010) 27:1629-51. doi: 10.3109/07420528.2010.510230

28. Verma S, Anderson TJ. Fundamentals of endothelial function for the clinical cardiologist. Circulation. (2002) 105:546-9. doi: 10.1161/hc0502.104540

29. Hirsch L, Shechter A, Feinberg MS, Koren-Morag N, Shechter M. The impact of early compared to late morning hours on brachial endothelial 
function and long-term cardiovascular events in healthy subjects with no apparent coronary heart disease. Int J Cardiol. (2011) 151:342-7. doi: 10.1016/j.ijcard.2010.08.069

30. McLoughlin SC, Haines P, FitzGerald GA. Clocks and cardiovascular function. Methods Enzymol. (2015) 552:211-28. doi: 10.1016/bs.mie.2014.11.029

31. Sibbing D, Gross L, Aradi D. Prevention of cardiovascular events with antiplatelet treatment: does time of intake matter for aspirin and ADP receptor blockers? Thromb Haemost. (2016) 115:3-6. doi: 10.1160/TH15-05-0430

32. Cesari M, Pahor M, Incalzi RA. Plasminogen activator inhibitor-1 (PAI-1): a key factor linking fibrinolysis and age-related subclinical and clinical conditions. Cardiovasc Ther. (2010) 28:e72-91. doi: 10.1111/j.1755-5922.2010.00171.x

33. Scheer FA, Shea SA. Human circadian system causes a morning peak in prothrombotic plasminogen activator inhibitor-1 (PAI1) independent of the sleep/wake cycle. Blood. (2014) 123:590-3. doi: 10.1182/blood-2013-07-517060

34. Baraldo M. The influence of circadian rhythms on the kinetics of drugs in humans. Expert Opin Drug Metabo Toxicol. (2008) 4:175-92. doi: 10.1517/17425255.4.2.175

35. Tacconelli S, Dovizio M, Di Francesco L, Meneguzzi A, D’Agostino I, Evangelista V, et al. Reduced variability to aspirin antiplatelet effect by the coadministration of statins in high-risk patients for cardiovascular disease. Clin Pharmacol Ther. (2018) 104:111-9. doi: 10.1002/cpt.1075

36. Windecker S, Kolh P, Alfonso F, Collet JP, Cremer J, Falk V, et al. 2014 ESC/EACTS guidelines on myocardial revascularization: the task force on myocardial revascularization of the European Society of Cardiology (ESC) and the European Association for Cardio-Thoracic Surgery (EACTS) developed with the special contribution of the European Association of Percutaneous Cardiovascular Interventions (EAPCI). Euro Heart J. (2014) 35:2541-619. doi: 10.1093/eurheartj/ehu278

37. Roger VL, Go AS, Lloyd-Jones DM, Adams RJ, Berry JD, Brown TM, et al. Heart disease and stroke statistics-2011 update: a report from the American Heart Association. Circulation. (2011) 123:e18-209. doi: 10.1161/CIR.0b013e31820c7a50

38. Needs CJ, Brooks PM. Clinical pharmacokinetics of the salicylates. Clin Pharmacokinet. (1985) 10:164-77. doi: 10.2165/00003088-198510020-00004

39. Wurtz M, Hvas AM, Jensen LO, Kaltoft AK, Tilsted HH, Kristensen SD, et al. 24-hour antiplatelet effect of aspirin in patients with previous definite stent thrombosis. Int. J. Cardiol. (2014) 175:274-9. doi: 10.1016/j.ijcard.2014.05.013

40. Henry P, Vermillet A, Boval B, Guyetand C, Petroni T, Dillinger JG, et al. 24hour time-dependent aspirin efficacy in patients with stable coronary artery disease. Thromb Haemost. (2011) 105:336-44. doi: 10.1160/TH10-02-0082

41. Vernstrom L, Funck KL, Grove EL, Laugesen E, Baier JM, Hvas AM, et al. Antiplatelet effect of aspirin during $24 \mathrm{~h}$ in patients with type 2 diabetes without cardiovascular disease. Thromb Res. (2018) 161:1-6. doi: 10.1016/j.thromres.2017.11.013

42. Grove EL, Storey RF, Kristensen SD. Can we improve the efficacy of low-dose aspirin? Thromb Haemost. (2014) 112:1077-8. doi: 10.1160/th14-08-0702

43. Warner TD, Nylander S, Whatling C. Anti-platelet therapy: cyclooxygenase inhibition and the use of aspirin with particular regard to dual anti-platelet therapy. Br J Clin Pharmacol. (2011) 72:619-33. doi: $10.1111 / j .1365-2125.2011 .03943 . x$

44. Lordkipanidze M. Platelet turnover in atherothrombotic disease. Curr Pharm Des. (2012) 18:5328-43. doi: 10.2174/138161212803 251952

45. Chen WH, Cheng X, Lee PY, Ng W, Kwok JY, Tse HF, et al. Aspirin resistance and adverse clinical events in patients with coronary artery disease. Am J Med. (2007) 120:631-5. doi: 10.1016/j.amjmed.2006.10.021

46. McAdam B, Keimowitz RM, Maher M, Fitzgerald DJ. Transdermal modification of platelet function: an aspirin patch system results in marked suppression of platelet cyclooxygenase. J Pharmacol Exp Ther. (1996) 277:559-64.

47. Scheer FA, Michelson AD, Frelinger AL III, Evoniuk H, Kelly EE, McCarthy $M$, et al. The human endogenous circadian system causes greatest platelet activation during the biological morning independent of behaviors. PLoS ONE. (2011) 6:e24549. doi: 10.1371/journal.pone.00 24549
48. Gow JA, Ebbeling L, Gerrard JM. The effect of regular and enteric-coated aspirin on bleeding time, thromboxane, and prostacyclin. Prost Leukotr Essen Fatty Acids. (1993) 49:515-20. doi: 10.1016/0952-3278(93)90040-4

49. Lorenz RL, Boehlig B, Uedelhoven WM, Weber PC. Superior antiplatelet action of alternate day pulsed dosing versus split dose administration of aspirin. Am J Cardiol. (1989) 64:1185-8. doi: 10.1016/0002-9149(89)90875-8

50. Capodanno D, Patel A, Dharmashankar K, Ferreiro JL, Ueno M, Kodali M, et al. Pharmacodynamic effects of different aspirin dosing regimens in type 2 diabetes mellitus patients with coronary artery disease. J Am Coll Cardiol. (2011) 57:E1910. doi: 10.1016/S0735-1097(11)61910-4

51. Sinzinger H, Kaliman J, Fitscha P, O'Grady J. Diminished platelet residence time on active human atherosclerotic lesions in-vivo-evidence for an optimal dose of aspirin? Prost Leukotr Essen Fatty Acids. (1988) 34:89-93. doi: 10.1016/0952-3278(88)90068-3

52. DiMinno G, Silver MJ, Cerbone AM, Murphy S. Trial of repeated low-dose aspirin in diabetic angiopathy. Blood. (1986) 68:886-91.

53. Hart RG, Leonard AD, Talbert RL, Pearce LA, Cornell E, Bovill E, et al. Aspirin dosage and thromboxane synthesis in patients with vascular disease. Pharmacotherapy. (2003) 23:579-84. doi: 10.1592/phco.23.5.579.32206

54. Tohgi H, Konno S, Tamura K, Kimura B, Kawano K. Effects of low-to-high doses of aspirin on platelet aggregability and metabolites of thromboxane A2 and prostacyclin. Stroke. (1992) 23:1400-3. doi: 10.1161/01.STR.23.10.1400

55. Saleem SM, Shah S, Shah BA, Dhobi GN, Feroz S. Role of platelet aggregation and effect of aspirin in ischemic strokes-a randomized study. JK Pract. (2000) 7:39-42. doi: 10.1161/01.STR.0000181081.09262.e1

56. DiChiara J, Bliden KP, Tantry US, Hamed MS, Antonino MJ, Suarez TA, et al. The effect of aspirin dosing on platelet function in diabetic and nondiabetic patients: an analysis from the aspirin-induced platelet effect (ASPECT) study. Diabetes. (2007) 56:3014-9. doi: 10.2337/db07-0707

57. Chamorro A, Escolar G, Revilla M, Obach V, Vila N, Reverter JC, et al. Ex vivo response to aspirin differs in stroke patients with single or recurrent events: a pilot study. J Neurol Sci. (1999) 171:110-4. doi: 10.1016/S0022-510X(99)00260-9

58. Perneby C, Wallen NH, Rooney C, Fitzgerald D, Hjemdahl P. Dose- and timedependent antiplatelet effects of aspirin. Thromb Haemost. (2006) 95:652-8. doi: 10.1160/TH05-10-0653

59. Racca C, van Diemen JK, Fuijkschot WW, Spit K, Bonten TN, Numans ME, et al. Aspirin intake in the morning is associated with suboptimal platelet inhibition, as measured by serum Thromboxane B2, during infarct-prone early-morning hours. Platelets. (2018) 1-7. doi: 10.1080/09537104.2018.1528347

60. Santos MT, Valles J, Aznar J, Lago A, Sanchez E, Cosin J, et al. Aspirin therapy for inhibition of platelet reactivity in the presence of erythrocytes in patients with vascular disease. J Lab Clin Med. (2006) 147:220-7. doi: 10.1016/j.lab.2005.12.005

61. Spectre G, Arnetz L, Ostenson CG, Brismar K, Li N, Hjemdahl P. Twice daily dosing of aspirin improves platelet inhibition in whole blood in patients with type 2 diabetes mellitus and micro- or macrovascular complications. Thromb Haemost. (2011) 106:491-9. doi: 10.1160/TH11-04-0216

62. McLeod LJ, Roberts MS, Cossum PA, Vial JH. The effects of different doses of some acetylsalicylic acid formulations on platelet function and bleeding times in healthy subjects. Scand J Haematol. (1986) 36:379-84. doi: 10.1111/j.1600-0609.1986.tb01753.x

63. Furuno T, Yamasaki F, Yokoyama T, Sato K, Sato T, Doi Y, et al. Effects of various doses of aspirin on platelet activity and endothelial function. Heart Vessels. (2011) 26:267-73. doi: 10.1007/s00380-010-0054-8

64. Addad F, Chakroun T, Elalamy I, Abderazek F, Chouchene S, Dridi Z, et al. Antiplatelet effect of once- or twice-daily aspirin dosage in stable coronary artery disease patients with diabetes. Inter J Hematol. (2010) 92:296-301. doi: 10.1007/s12185-010-0652-3

65. van Diemen JJ, Fuijkschot WW, Wessels TJ, Veen G, Smulders YM, Thijs A. Evening intake of aspirin is associated with a more stable 24-h platelet inhibition compared to morning intake: a study in chronic aspirin users. Platelets. (2016) 27:351-6. doi: 10.3109/09537104.2015.1107536

66. Bonten TN, Snoep JD, Assendelft WJ, Zwaginga JJ, Eikenboom J, Huisman MV, et al. Time-dependent effects of aspirin on blood pressure and morning platelet reactivity: a randomized cross-over trial. Hypertension. (2015) 65:74350. doi: 10.1161/HYPERTENSIONAHA.114.04980 
67. Krasinska B, Paluszkiewicz L, Miciak-Lawicka E, Krasinski M, Rzymski P, Tykarski A, et al. The effect of acetylsalicylic acid dosed at bedtime on the anti-aggregation effect in patients with coronary heart disease and arterial hypertension: a randomized, controlled trial. Cardiol J. (2018). doi: 10.5603/CJ.a2018.0142. [Epub ahead of print].

68. Garcia Rodriguez LA, Martin-Perez M, Hennekens CH, Rothwell PM, Lanas A. Bleeding risk with long-term low-dose aspirin: a systematic review of observational studies. PLoS ONE. (2016) 11:e0160046. doi: 10.1371/journal.pone.0160046

69. Claxton AJ, Cramer J, Pierce C. A systematic review of the associations between dose regimens and medication compliance. Clin Ther. (2001) 23:1296-310. doi: 10.1016/S0149-2918(01)8 0109-0

70. Bem D, Lordkipanidze M, Hodgkinson J, Stevens S, Bayliss S, Moore D, et al. The effects of different aspirin dosing frequencies and the timing of aspirin intake in primary and secondary prevention of cardiovascular disease: a systematic review. Clin Pharmacol Ther. (2016) 100:500-12. doi: $10.1002 /$ cpt.438

Conflict of Interest Statement: The authors declare that the research was conducted in the absence of any commercial or financial relationships that could be construed as a potential conflict of interest.

Copyright $\odot 2019$ Buurma, van Diemen, Thijs, Numans and Bonten. This is an open-access article distributed under the terms of the Creative Commons Attribution License (CC BY). The use, distribution or reproduction in other forums is permitted, provided the original author(s) and the copyright owner(s) are credited and that the original publication in this journal is cited, in accordance with accepted academic practice. No use, distribution or reproduction is permitted which does not comply with these terms. 